\title{
Carbohydrate intake and cardiometabolic risk factors in high BMI African American children
}

Sushma Sharma ${ }^{1,2^{*}}$, Lindsay S Roberts ${ }^{1,2}$, Robert H Lustig ${ }^{1,3}$, Sharon E Fleming ${ }^{1,2}$

\begin{abstract}
The aim of this study was to evaluate the relationship between intakes of subgroups of energy-providing carbohydrate, and markers of cardiometabolic risk factors in high BMI African American (AA) children.

A cross sectional analysis was performed on data from a sample of 9-11 year old children $(n=95)$ with BMl greater than the $85^{\text {th }}$ percentile. Fasting hematological and biochemical values for selected markers of cardiometabolic risk factors were related to intakes of carbohydrates and sugars.

After adjusting for gender, pubertal stage and waist circumference, multivariate regression analysis showed that higher intakes of carbohydrate (with fat and protein held constant) were associated with higher plasma concentrations of triglycerides (TG), VLDL-C, IDL-C, and worse insulin resistance (homeostasis model assessment of insulin resistance, HOMA-IR). After dividing carbohydrate into non-sugar versus sugar fractions, sugars were significantly related to higher TG, VLDL-C, IDL-C, lower adipocyte fatty acid insulin sensitivity (ISI-FFA), and was closely associated with increased HOMA-IR. Similar trends were observed for sugars classified as added sugars, and for sugars included in beverages. Further dividing sugar according to the food group from which it was consumed showed that consuming more sugar from the candy/soda food group was highly significantly associated with increased TG, VLDL-C, IDL-C and closely associated with increased HOMA-IR. Sugars consumed in all fruit-containing foods were significantly associated with lower ISI-FFA. Sugars consumed as fruit beverages was significantly associated with VLDL-C, IDL-C and ISI-FFA whereas sugars consumed as fresh, dried and preserved fruits did not show significant associations with these markers.

Sugars consumed from in all dairy foods were significantly associated with higher TG, VLDL-C and IDL-C, and with significantly lower HDL-C and ISI-FFA. These effects were associated with sugars consumed in sweetened dairy products, but not with sugars consumed in unsweetened dairy products. This analysis suggests that increases in carbohydrate energy, especially in the form of sugar, may be detrimental to cardiometabolic health in high BMl children.
\end{abstract}

\section{Introduction}

Childhood obesity has reached epidemic levels in developed countries [1]. Obesity during childhood and adolescence is associated with a number of cardiometabolic risk factors [2]. Evidence suggests that diet during childhood may have important implications for the development of obesity and chronic disease in later life. Also, it has been established that energy intake from specific macronutrients plays a more important role in the development of obesity and metabolic complications than does total energy intake alone. Our recent findings suggest that the effect of increased energy on risk of

\footnotetext{
* Correspondence: sushma@berkeley.edu

${ }^{1}$ The Dr Robert C and Veronica Atkins Center for Weight and Health, University of California, Berkeley, CA 94720-3104, USA
}

developing cardiometabolic risk factors is in part influenced by the source of that energy [2].

The African American (AA) population has been shown to be at higher risk for both obesity and the metabolic syndrome than are Caucasians [3]. As the prevalence of obesity [4] and metabolic syndrome in AA children continues to increase [5], management of risk factors must begin at an early age. Recently, we concluded that increases in energy intake from carbohydrate were associated with undesirable effects, including increases in TG, VLDL-C, IDL-C and HOMA-IR [2]. More recently, increased attention to type of carbohydrate, rather than total carbohydrate, has begun to clarify the role of carbohydrate subgroups in the obesity epidemic among adults; however studies of this nature 
have not yet been performed in children. Numerous short-term studies have shown that diets high in carbohydrates, particularly sugars, and even more particularly sucrose and fructose, increase serum TG concentrations and decrease serum HDL cholesterol; and may therefore increase the risk of CVD [6,7]. It is unclear which specific subgroups of carbohydrates are possibly related to cardiometabolic risk factors in AA children. In this study we evaluated the relationship between intakes of different subgroups of carbohydrates, and selective markers of cardiometabolic risk factors in high BMI AA children.

\section{Methods}

\section{Subjects}

Subjects included in this analysis represented a crosssectional convenience sample of 9-11 year-old African American children enrolled in the Taking Action Together study, an inner-city YMCA-based intervention trial that aimed to reduce risk factors for type 2 diabetes. A total of 128 African-American (AA) children (56 boys, 65 girls) were evaluated in this cross-sectional analysis, and a full set of data was available for 99 children.

All participants had BMIs above the $85^{\text {th }}$ percentile, fasting glucose $<120 \mathrm{mg} / \mathrm{dl}$, were free from any known metabolic diseases, and were not taking medications known to affect the study outcomes. Parental informed consent was obtained for all subjects, and all protocols were approved by institutional review boards at the University of California, Berkeley and San Francisco. Anthropometric characteristics were measured using procedures previously described [8].

\section{Biochemical measurements}

Subjects reported to Children's Hospital and Research Center, Oakland, CA after a $12 \mathrm{hr}$ overnight fast when their blood was drawn. Plasma lipids (lipoprotein cholesterol and triglycerides) were measured by a comprehensive lipoprotein analysis (VAP-cholesterol method) performed by a commercial lab (Laboratory Corporation of America) as previously described [2]. Fasting concentrations of plasma glucose, serum insulin, and non-esterified fatty acids were measured, and these values used to calculate insulin resistance (HOMA-IR) and adipocyte insulin sensitivity (ISI-FFA) [2,9]. Pubertal development was assessed by measurements of serum luteinizing hormone (LH) in boys, and estradiol and LH in girls. Children were classified into pubertal stages 1 through 5 using literature-derived values $[2,10]$.

\section{Energy intake}

Three-day food diaries were used to assess intakes of nutrients [11]. Macronutrient intakes were determined using the USDA nutrient database [12]. Foods listed on the 3-day food diaries were labeled according to the 8digit USDA food codes; weights of foods consumed were entered into the software; and computer programs were used to calculate the 3-day average intakes of total energy, macronutrients (carbohydrate, protein, fat) and total sugars. Intakes of added sugars were determined using the MyPyramid Equivalents Database [13]. Computer programs were used also to calculate intakes of sugars from beverages (USDA food codes were identified for all beverages including sodas, fruit-flavored drinks, fruit juice, energy/sports drinks, sweetened/flavored milks including milk shakes, tea and coffee), candy/soda-like foods (USDA food codes, 90 millions), cereal foods (USDA food codes, 50 millions), all fruitcontaining foods (USDA food codes, 60 millions), fresh, dried and preserved fruit (USDA food code 60-63 \& 6569 millions), fruit beverages such as fruit juice and nondairy fruit smoothies (USDA food code 64 millions), all dairy-containing foods (USDA food codes, 10 millions), dairy including unflavored milk, cream, whipped toppings and cheese (USDA food code 10-11.40 million; 12 \& 14-19 millions), and dairy including flavored milk, milkshakes, ice cream, yogurt, and milk puddings (USDA food code 11.41-12 million; 13 \& 14 millions). Non-sugar intakes were determined by difference (total carbohydrate intake minus sugar intake). Macronutrient and sugar intakes were calculated as a percentage of total energy intakes by assuming an energy value of 4 $\mathrm{kcal} / \mathrm{g}$ carbohydrate and protein, and $9 \mathrm{kcal} / \mathrm{g}$ fat. Analyses were carried out following the protocol for the National Health and Nutrition Examination Survey (NHANES), with no quantification or exclusion for underreporting or over reporting.

\section{Statistical analysis}

Statistical procedures were performed using SPSS for Windows version 16.0 (SPSS Inc, Chicago, IL). Statistical significance was defined to be $\mathrm{p} \leq 0.05$. Results with $0.05<\mathrm{p}<0.10$ are noted to show close associations. Differences in anthropometric indices and lipoprotein profiles in boys versus girls were performed using independent t-tests. Dixon's test for outliers was used to identify unusual values. When identified, all data for that participant were excluded from further analyses. Using Dixon's test, data for 4 of the 99 children were excluded; thus, data are presented for a total of 95 children (47 boys, 48 girls). Data were not significantly skewed for any of the variables of interest. Multiple linear regression analyses were used to assess the relationship of intake from different carbohydrate subgroups to TG, VLDL-C, IDL-C, HDL-C, HOMA-IR and ISI-FFA, after adjusting for gender, pubertal stage, waist circumference of the participating child, protein intake and fat 
intake. These markers were selected for further study since they were found previously to be significantly associated with total carbohydrate intake [2].

\section{Results}

In comparison to boys, girls in this cohort had significantly higher values for measures of body fatness and were less insulin sensitive (Table 1). Carbohydrate contributed on average, nearly $50 \%$ of energy; sugars contributed $\sim 50 \%$ of total carbohydrate consumed (Table 2 ) and beverages provided $\sim 40 \%$ of total sugar.

Using data from a similar cohort, we previously reported [2] that higher intakes of carbohydrate (fat and protein held constant) were associated with higher TG, VLDL-C, IDL-C, HOMA-IR and lower ISI-FFA, as observed also for this cohort (Table 3 Model 1). After dividing carbohydrate intake into non-sugar versus sugar fractions (Table 3 Model 2), higher intakes of sugar was associated with significantly higher TG, VLDL-C, IDL-C, and lower ISI-FFA, and was closely associated with increased HOMA-IR. When the sugar subgroup was further divided into added sugars versus non-added (other) sugars, added sugars was associated with increased TG, VLDL-C, TG and HOMA-IR and closely associated with increased IDL-C (Table 3 Model 3).

In further analysis, when sugar was subdivided according to the dietary food group from which it was consumed, beverage sugar was significantly related to elevated TG, VLDL-C and IDL-C, whereas non-beverage

Table 1 Characteristics of participating children $(n=95)$. Boys $(n=47) \quad$ Girls $(n=48) \quad p$-value $^{a}$ Mean \pm SD

\begin{tabular}{lccl}
\hline Anthropometrics & & & \\
Age (years) & $10.4 \pm 1.0$ & $10.2 \pm 1.1$ & $n s$ \\
Pubertal stage (1-5) & $2.6 \pm 1.7$ & $3.5 \pm 1.2$ & 0.004 \\
Height (m) & $149.3 \pm 8.9$ & $151.7 \pm 9.2$ & $n s$ \\
Weight (kg) & $59.9 \pm 18.2$ & $66.8 \pm 14.2$ & 0.043 \\
Body fat (\%) & $32.9 \pm 9.5$ & $40.2 \pm 7.9$ & $<0.001$ \\
BMI-z score & $1.91 \pm 0.5$ & $2.1 \pm 0.4$ & 0.020 \\
WC (cm) & $85.3 \pm 15.4$ & $91.0 \pm 12.8$ & $n s$ \\
Biochemical parameters & & & \\
TG (mmol/l) & $66.1 \pm 33.6$ & $73.2 \pm 23.4$ & $n s$ \\
VLDL-C (mmo//l) & $15.5 \pm 4.7$ & $16.0 \pm 3.2$ & $n s$ \\
IDL-C (mmol/l) & $8.9 \pm 4.9$ & $9.5 \pm 4.8$ & $n s$ \\
HOMA-IR & $1.9 \pm 1.2$ & $2.9 \pm 1.4$ & $<0.001$ \\
ISI-FFA & $0.5 \pm 0.2$ & $0.3 \pm 0.2$ & $<0.001$ \\
Dietary variables & & & \\
Total energy (kcal/day) & $1833 \pm 684$ & $1801 \pm 619$ & $n s$ \\
Carbohydrate (g/day) & $218 \pm 91$ & $232 \pm 87$ & $n s$ \\
\hline
\end{tabular}

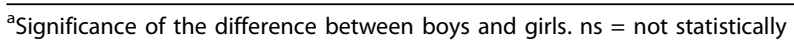
significant $(p>0.05)$ sugar intakes were not (Table 3 Model 4). Finally, of the 9 possible groups into which foods are divided using the USDA food codes, four food groups were found to contribute $94 \%$ of the total sugar intake (Table 2). When included simultaneously in a single regression model (Table 3 Model 5), increasing consumption of sugar from the candy/soda food group was associated with highly significant increases in TG, VLDL-C and IDL-C and was closely associated with increases in HOMA-IR. Consuming sugars from cereal foods was not significantly associated with these risk factors. Intake of sugars from the total fruit group was associated with significantly lower ISI-FFA and was closely associated with increased IDL-C. Sugar intake from all dairy foods was associated with highly significant increases in TG, VLDL-C and IDL-C and with decreased HDL-C and ISI-FFA.

When the total fruit group was further divided, consumption of sugars from fruit-containing beverages was significantly associated with increased VLDL-C and IDL-C, and with decreased ISI-FFA. By contrast, sugar intakes from fresh, dried and preserved fruits did not show any significant associations with these markers (Table4 Model 6).

When the total dairy group was sub-divided, sugar intakes from sweetened dairy products showed significant association with increased TG and with decreased HDL-C and ISI-FFA, whereas sugar intake from unsweetened dairy foods did not (Table 4 Model 7).

\section{Discussion}

Our main outcomes highlight the association of intakes of carbohydrate from different subgroups with key markers of cardiometabolic risk in high BMI AA children. Importantly, the variance in TG, VLDL-C, IDL-C and ISI-FFA contributed by total carbohydrate appeared to be mainly from sugars, suggesting that sugar fractions contributed to the undesirable effects of increasing total carbohydrate intake. Thus, increases in total carbohydrate intake, due to increased sugar intake, were associated with undesirable increases in several classes of plasma lipids. Additionally, sugar intake was closely associated with decreases in HOMA-IR. (Table 3 Model 2).

New evidence on the relationship between intake of sugars and cardiovascular health has emerged since the last American Heart Association (AHA) scientific statement was published in 2002 [14]. In 2006, the AHA revised their diet and lifestyle recommendations, adding a recommendation to minimize intakes of beverages and foods with added sugars [15]. Other recent findings have suggested that higher consumption of added sweeteners such as high fructose corn syrup can lead to weight gain, increased insulin resistance, a lowering of 
Table 3 Relationship between intakes of carbohydrate sugar subgroups and cardiometabolic risk factors, assessed using five multiple linear regression models $(n=95)$.

\begin{tabular}{|c|c|c|c|c|c|c|c|c|c|}
\hline & \multicolumn{2}{|l|}{ Model 1} & \multicolumn{2}{|c|}{ Model 2} & \multirow{2}{*}{\multicolumn{2}{|c|}{$\frac{\text { Model } 3}{\text { Sugars }}$}} & & & \\
\hline & \multirow[t]{2}{*}{ Total CHO } & \multirow[t]{2}{*}{ Non sugar $\mathrm{CHO}$} & \multirow[t]{2}{*}{ Sugars } & \multirow{2}{*}{$\begin{array}{l}\text { Non sugar } \\
\text { CHO }\end{array}$} & & & & & \\
\hline & & & & & Added sugars & Others & & & \\
\hline$\overline{\mathrm{TG}}$ & $0.357^{*}$ & -0.036 & $0.355^{* *}$ & 0.007 & $0.408^{* *}$ & -0.062 & & & \\
\hline VLDL-C & $0.460^{* *}$ & 0.078 & $0.379^{* *}$ & 0.090 & $0.335^{* *}$ & 0.097 & & & \\
\hline IDL-C & $0.497^{* *}$ & 0.109 & $0.394^{* *}$ & 0.085 & $0.239^{\#}$ & $0.277^{*}$ & & & \\
\hline HDL-C & -0.131 & -0.017 & -0.111 & -0.021 & -0.100 & -0.025 & & & \\
\hline ISI-FFA & $-0.273^{*}$ & -0.048 & $-0.224^{*}$ & -0.020 & -0.096 & $-0.222^{*}$ & & & \\
\hline \multirow{4}{*}{$\begin{array}{l}\text { HOMA- } \\
\text { IR }\end{array}$} & $0.345^{* *}$ & 0.192 & $0.200^{\#}$ & 0.220 & $0.241^{*}$ & -0.054 & & & \\
\hline & \multicolumn{4}{|c|}{ Model 4} & \multicolumn{5}{|c|}{ Model 5} \\
\hline & \multirow{2}{*}{$\begin{array}{l}\text { Non-sugar } \\
\mathrm{CHO}\end{array}$} & \multicolumn{2}{|c|}{ Sugar Source } & \multirow[t]{2}{*}{ Non-sugar $\mathrm{CHO}$} & \multicolumn{5}{|c|}{ Sugar Source } \\
\hline & & $\begin{array}{l}\text { Beverage } \\
\text { sugars }\end{array}$ & Other & & $\begin{array}{l}\text { Candy/soda } \\
\text { group } 1\end{array}$ & $\begin{array}{l}\text { Cereal } \\
\text { group }^{2}\end{array}$ & $\begin{array}{l}\text { Fruit } \\
\text { group }\end{array}$ & $\begin{array}{l}\text { Dairy } \\
\text { group }\end{array}$ & Other \\
\hline TG & 0.004 & $0.286^{*}$ & 0.148 & 0.153 & $0.329^{* *}$ & -0.069 & -0.048 & $0.239^{*}$ & 0.009 \\
\hline VLDL-C & 0.146 & $0.350^{* *}$ & 0.108 & 0.237 & $0.294^{*}$ & -0.074 & 0.090 & $0.239 *$ & 0.054 \\
\hline IDL-C & 0.142 & $0.299^{*}$ & 0.185 & 0.251 & $0.275^{*}$ & -0.062 & $0.201 \#$ & $0.270^{*}$ & $0.239^{\#}$ \\
\hline HDL-C & -0.041 & -0.111 & -0.022 & -0.154 & -0.020 & 0.017 & 0.056 & $-0.316^{* *}$ & -0.141 \\
\hline ISI-FFA & -0.038 & -0.122 & -0.160 & -0.173 & -0.069 & 0.116 & $-0.198^{*}$ & $-0.266^{* *}$ & -0.074 \\
\hline HOMA & 0.187 & 0.116 & 0.135 & $0.283^{\#}$ & $0.167^{\#}$ & -0.050 & 0.027 & 0.115 & -0.013 \\
\hline
\end{tabular}

*** $\mathrm{p}<0.001,{ }^{* *} \mathrm{p}<0.01,{ }^{*} \mathrm{p}<0.05,{ }^{*} \mathrm{p}=0.05-0.10$. In addition to the variables shown for each model, other variables entered simultaneously into each model included gender, pubertal stage, waist circumference, protein intake and fat intake. Values presented are standardized regression coefficients and level of significance.

${ }^{1}$ Candy, confections, fruit flavored drinks, sodas, syrups (USDA food code 90 Millions).

2 Breakfast cereals, cakes, cookies, crackers and pastries (USDA food code 50 Millions).

${ }^{3}$ Fruit products including fresh, dried and preserved fruit; fruit juice; non-dairy fruit smoothies (USDA food code 60 Millions).

${ }^{4}$ Dairy including unflavored fluid milk, cream, cheese, flavored milk, milkshakes, ice cream, yogurt, and milk puddings (USDA food code 10 Millions).

Table 4 Relationships (standardized regression coefficients and level of significance) between intakes of fruit and dairy subgroups and cardiometabolic risk factors, assessed using two multiple linear regression models $(n=95)$.

\begin{tabular}{|c|c|c|c|c|c|c|c|c|}
\hline & \multicolumn{4}{|c|}{ Model 6} & \multicolumn{4}{|c|}{ Model 7} \\
\hline & \multirow{2}{*}{$\begin{array}{l}\text { Non-sugar } \\
\mathrm{CHO}\end{array}$} & \multicolumn{3}{|c|}{ Sugar Source } & \multirow{2}{*}{$\begin{array}{l}\text { Non-sugar } \\
\mathrm{CHO}\end{array}$} & \multicolumn{3}{|c|}{ Sugar Source } \\
\hline & & $\begin{array}{l}\text { Fruit (no } \\
\text { beverages) }^{1}\end{array}$ & $\begin{array}{l}\text { Fruit-containing } \\
\text { beverages }^{2}\end{array}$ & Other & & $\begin{array}{l}\text { Dairy, un- } \\
\text { sweetened }^{3}\end{array}$ & $\begin{array}{l}\text { Dairy, } \\
\text { sweetened }^{4}\end{array}$ & Other \\
\hline$\overline{\mathrm{TG}}$ & 0.006 & -0.073 & 0.013 & $0.395^{* *}$ & 0.021 & 0.005 & $0.242^{*}$ & $0.249^{\#}$ \\
\hline $\begin{array}{l}\text { VLDL- } \\
\text { C }\end{array}$ & 0.096 & -0.101 & $0.232^{*}$ & $0.315^{*}$ & 0.115 & 0.013 & $0.197^{\#}$ & $0.299^{*}$ \\
\hline IDL-C & 0.097 & 0.066 & $0.241^{*}$ & $0.281^{*}$ & 0.126 & 0.039 & 0.141 & $0.341^{*}$ \\
\hline HDL-C & -0.046 & 0.124 & -0.026 & -0.140 & -0.121 & -0.097 & $-0.251^{*}$ & 0.037 \\
\hline $\begin{array}{l}\text { ISI- } \\
\text { FFA }\end{array}$ & -0.027 & -0.063 & $-0.195^{*}$ & -0.123 & -0.098 & -0.047 & $-0.171^{*}$ & -0.139 \\
\hline HOMA & 0.203 & 0.012 & 0.027 & $0.198^{\#}$ & 0.213 & -0.027 & 0.123 & 0.153 \\
\hline
\end{tabular}

*** $\mathrm{p}<0.001,{ }^{* *} \mathrm{p}<0.01,{ }^{*} \mathrm{p}<0.05,{ }^{*} \mathrm{p}=0.05-0.10$. In addition to the variables shown for each model, other variables entered simultaneously into each model included gender, pubertal stage, waist circumference, protein intake and fat intake. Values presented are standardized regression coefficients and level of significance.

${ }^{1}$ Fresh, dried and preserved fruit; (USDA food code 60-63 \& 65-69 Millions).

${ }^{2}$ Fruit-containing beverages including fruit juice, non-dairy fruit smoothies (USDA food code 64 Millions).

${ }^{3}$ Dairy including unflavored milk, cream (including whipped toppings) and cheese (USDA food code 10-11.40 Million; 12 \& 14-19 Millions).

${ }^{4}$ Dairy including flavored milk, milkshakes, ice cream, yogurt, and milk puddings (USDA food code 11.41-11.99 Million \& 13 Millions). 
children. When these food groups were further divided, this risk was associated with sugars in fruit-containing beverages and with sweetened dairy foods (Table 4). Thus, our results support AHA's diet and lifestyle recommendations, to minimize intakes of beverages and foods with added sugars [15]. As no positive association was observed between intakes of non-beverage fruitcontaining foods and these risk factors, this strengthens the recommendations for increasing fresh fruit consumption over beverages in children. Similarly, "healthy", unsweetened dairy foods were not significantly associated with increased risk, nor were they were associated with reduction in risk factors. Thus, recommendations that these children increase dairy intakes as a means of improving bone health should focus on the unsweetened dairy foods, and not on sweetened dairy.

Limitations of this study include restriction to lowincome, inner-city, African American children and exclusion of children with BMI's less than the $85^{\text {th }}$ percentile when matched for age and gender. These limitations preclude comparisons among children of different races, ages and socioeconomic backgrounds, and comparisons with lower BMI children. The limitations inherent in collecting dietary data, regardless of population, are also recognized. This is a cross-sectional analysis of data, precluding a cause and effect relationship. Future longitudinal studies, with measurements at several time-points, would be needed to evaluate a causal relationship. Also, replications in longitudinal studies with larger sample sizes, and in multiracial cohorts are warranted.

\section{Conclusion}

Based on our analysis, we conclude that increases in carbohydrate energy in the form of sugars were associated with undesirable increases in several classes of plasma lipids and with decreases in both hepatic glucose and adipocyte fatty acid insulin sensitivity. Higher intakes of sugars from the candy/soda food group, from fruit-containing beverages, and from sweetened dairy foods were associated with increases in several cardiometabolic risk factors. This analysis suggests that increases in many types and sources of sugar may be detrimental to cardiometabolic health in high BMI children.

\section{Conflict of interests}

The authors declare that they have no competing interests.

\footnotetext{
Abbreviations

AA: African American; BMl: Body mass index; CVD: Cardio vascular disease; HOMA-IR: Homeostasis model assessment of insulin resistance; IDL-C: Intermediate density lipoprotein cholesterol; ISI-FFA: Fatty acid insulin
}

sensitivity; NEFA: Non-esterified fatty acids; TG: Triglyceride; VLDL-C: Very low density lipoprotein cholesterol; HDL-C: High density lipoprotein cholesterol; WC: Waist circumference.

\section{Acknowledgements}

The authors gratefully acknowledge the collaboration and excellent assistance provided by the YMCA of the East Bay in Oakland, CA. Essential funding was provided by USDA CSREES grants 2004-35214-14254 and 200535215-15046, the Agriculture Experiment Station, the YMCA, the Robert C and Veronica Atkins Foundation and the Lawrence and Victoria Johnson family. The authors are indebted to the participating children and their families, to the large number of UC Berkeley student assistants, and to Dr. Aarthi Raman, Barbara Green, Rita Mitchell and Mark D. Fitch. Valued consultants on this project include all members of the Advisory Board of the Taking Action Together Project.

\section{Author details}

${ }^{1}$ The Dr Robert $C$ and Veronica Atkins Center for Weight and Health, University of California, Berkeley, CA 94720-3104, USA. ²Department of Nutritional Sciences and Toxicology, University of California, Berkeley, CA 94720-3104, USA. ${ }^{3}$ Division of Pediatric Endocrinology, University of California, San Francisco, CA 94143, USA.

\section{Authors' contributions}

Contributor's list: SS contributed in statistical analysis, preparation of the manuscript and submission. LSR participated in the development of the protocol, analytical framework for the study and patient screening. $\mathrm{RHL}$ provided expertise as a pediatric endocrinologist and child health specialist. SEF was the principal investigator of the study. She supervised the design and execution of the study and manuscript. All authors have read and approved the final manuscript.

Received: 5 December 2009

Accepted: 9 February 2010 Published: 9 February 2010

\section{References}

1. Ogden CL, Carroll MD, Curtin LR, McDowell MA, Tabak CJ, Flegal KM: Prevalence of overweight and obesity in the United States, 1999-2004. JAMA 2006, 295:1549-1555.

2. Sharma S, Roberts LS, Hudes ML, Lustig RH, Fleming SE: Macronutrient intakes and cardiometabolic risk factors in high BMI African American children. Nutrition and Metabolism 2009, 6:41.

3. Egede LE, Dagogo-Jack S: Epidemiology of type 2 diabetes: focus on ethnic minorities. Med Clin North Am 2005, 89:949-975.

4. Ogden $C L$, Carroll MD, Flegal KM: High body mass index for age among US children and adolescents, 2003-2006. JAMA 2008, 299:2401-5.

5. Dabelea D, Pettitt DJ, Jones KL, Arslanian SA: Type 2 diabetes mellitus in minority children and adolescents. An emerging problem. Endocrinol Metab Clin North Am 1999, 28:709-729.

6. Katan MB, Grundy SM, Willett WC: Should a low-fat, high-carbohydrate diet be recommended for everyone? Beyond low-fat diets. N Engl J Med 1997, 337:563-6.

7. Parks EJ, Hellerstein MK: Carbohydrate-induced hypertriacylglycerolemia: historical perspective and review of biological mechanisms. Am J Clin Nutr 2000, 71:412-33.

8. Raman A, Fitch M, Hudes M, Lustig RH, Murray CB, Ikeda JP, Fleming SE: Baseline correlates of insulin resistance in inner city high-BMI AfricanAmerican children. Obesity 2008, 16:2039-2045.

9. Reinehr T, Kiess W, Andler W: Insulin sensitivity indices of glucose and free fatty acid metabolism in obese children and adolescents in relation to serum lipids. Metabolism 2005, 54:397-402.

10. Raman A, Lustig R, Fitch MD, Fleming S: Accuracy of self assessed tanner staging against hormonal assessment of sexual maturation in overweight African-American children. J Pediatr Endocrinol Metab 2009, 22:609-622.

11. Crawford PB, Obarzanek E, Morrison J, Sabry Zl: Comparative advantage of 3-day food records over 24-hour recall and 5-day food frequency validated by observation of 9- and 10-year-old girls. J Am Diet Assoc 1994, 94:626-630.

12. Services USDAARS: What's in the Foods You Eat search tool, version 2.0. USDA: Agricultural Research Services.http://www.ars.usda.gov. 
13. Friday JE, Bowman SA: MyPyramid equivalents database for USDA survey food codes, 1994-version 1.0. U.S. Department of Agriculture, Agriculture Research Service.http://www.barc.usda.gov/bhnrc/cnrg

14. Howard BV, Wylie-Rosett J: Sugar and cardiovascular disease: a statement for healthcare professionals from the Committee on Nutrition of the Council on Nutrition, Physical Activity, and Metabolism of the American Heart Association [published correction appears in Circulation. 2003; 107:2166]. Circulation 2002, 106:523-527.

15. Lichtenstein AH, Appel $\sqcup$, Brands M, Carnethon M, Daniels S, Franch HA, Franklin B, Kris-Etherton P, Harris WS, Howard B, Karanja N, Lefevre M, Rudel L, Sacks F, Van Horn L, Winston M, Wylie-Rosett J: Diet and lifestyle recommendations revision 2006: a scientific statement from the American Heart Association Nutrition Committee Circulation. 2006, 114:82-96.

16. Bray GA, Nielsen SJ, Popkin BM: Consumption of high-fructose corn syrup in beverages may play a role in the epidemic of obesity. Am J Clin Nutr 2004, 79:537-543.

17. Elliott SS, Keim NL, Stern JS, Teff K, Havel PJ: Fructose, weight gain, and the insulin resistance syndrome. Am J Clin Nutr 2002, 76:911-922.

18. Nguyen S, Choi HK, Lustig RH, Hsu CY: Sugar-sweetened beverages, serum uric acid, and blood pressure in adolescents. J Pediatr 2009, 154:807-813.

19. Johnson RK, Appel LJ, Brands M, Howard BV, Lefevre M, Lustig RH, Sacks F, Steffen LM, Wylie-Rosett J, on behalf of the American Heart Association Nutrition Committee of the Council on Nutrition, Physical Activity, and Metabolism and the Council on Epidemiology and Prevention: Dietary Sugars Intake and Cardiovascular Health. A Scientific Statement From the American Heart Association. Circulation 2009, 120:1011-1020.

20. Dhingra R, Sullivan L, Jacques PF, Wang TJ, Fox CS, Meigs JB, D'Agostino RB, Gaziano JM, Vasan RS: Soft drink consumption and risk of developing cardiometabolic risk factors and the metabolic syndrome in middleaged adults in the community. Circulation 2007, 116:480-488.

21. James J, Thomas P, Cavan D, Kerr D: Preventing childhood obesity by reducing consumption of carbonated drinks: cluster randomized controlled trial (published correction appears). BMJ 2004, 328:1236-1237.

22. Ludwig DS, Peterson KE, Gortmaker SL: Relation between consumption of sugar-sweetened drinks and childhood obesity: a prospective, observational analysis. Lancet 2001, 357:505-508.

23. Schulze MB, Manson JE, Ludwig DS, Colditz GA, Stampfer MJ, Willett WC, Hu FB: Sugar-sweetened beverages, weight gain, and incidence of type 2 diabetes in young and middle-aged women. JAMA 2004, 292:927-934.

24. Vanselow MS, Pereira MA, Neumark-Sztainer D, Raatz SK: Adolescent beverage habits and changes in weight over time: findings from Project EAT. Am J Clin Nutr 2009, 90:1489-95.

doi:10.1186/1743-7075-7-10

Cite this article as: Sharma et al:: Carbohydrate intake and cardiometabolic risk factors in high BMI African American children.

Nutrition \& Metabolism 2010 7:10

\section{Submit your next manuscript to BioMed Central and take full advantage of:}

- Convenient online submission

- Thorough peer review

- No space constraints or color figure charges

- Immediate publication on acceptance

- Inclusion in PubMed, CAS, Scopus and Google Scholar

- Research which is freely available for redistribution

Submit your manuscript at www.biomedcentral.com/submit
Biomed Central 